\title{
Présentation de la rubrique
}

\section{Serge Bahuchet}

\section{(2) OpenEdition}

\section{Journals}

\section{Electronic version}

URL: http://journals.openedition.org/ethnoecologie/2879

DOI: 10.4000/ethnoecologie.2879

ISSN: 2267-2419

\section{Publisher}

Laboratoire Eco-anthropologie et Ethnobiologie

\section{Electronic reference}

Serge Bahuchet, « Présentation de la rubrique », Revue d'ethnoécologie [Online], 10 | 2016, Online since 04 January 2017, connection on 24 September 2020. URL : http://journals.openedition.org/ ethnoecologie/2879; DOI : https://doi.org/10.4000/ethnoecologie.2879

This text was automatically generated on 24 September 2020

\section{cc) (i) (9)}

Revue d'ethnoécologie est mis à disposition selon les termes de la licence Creative Commons Attribution - Pas d'Utilisation Commerciale - Pas de Modification 4.0 International. 


\title{
Présentation de la rubrique
}

\author{
Serge Bahuchet
}

1 Dès ses origines en 1964, le laboratoire d'ethnobotanique du Muséum, créé et dirigé par Roland Portères, incorpore dans ses collections quelques objets constitués de matières végétales. Raymond Pujol, chargé peu après de créer une section ethnozoologique, donnera plus d'importance aux collections d'objets, d'abord en Afrique centrale, puis en France. Il formera ses étudiants à cette pratique, consistant à rapporter de leurs séjours de recherche sur le terrain des témoins de la vie matérielle des communautés étudiées.

2 Cinquante ans plus tard, ce sont plus de 3000 objets de la vie quotidienne qui ont été collectés par les successeurs de Portères et Pujol, provenant de tous les continents, Afrique, Asie, Amérique, Europe... Ils concernent les activités en relation avec la biodiversité (chasse, pêche, collecte, agriculture, élevage), avec l'alimentation ainsi qu'avec les soins du corps.

Cette collection, qui s'enrichit régulièrement, est désormais conservée au Musée de l'Homme depuis sa rénovation en 2015. Elle est appelée à y rejoindre les collections d'ethnologie, pour constituer l'Unité de conservation « anthropologie culturelle » des collections du Muséum.

4 De cet ensemble font également partie les spécimens naturalistes, ethnobotaniques (plantes en herbier, matières végétales, graines...) et ethnozoologiques (animaux entiers ou en fragments -cornes, peaux, coquilles...) porteurs d'informations culturelles (noms vernaculaires, usages...), qui comptent plus de 100000 numéros. 